\title{
Research on Corporate Public Contribution, Employee Satisfaction and Performance in Private Enterprises
}

\author{
Xin Yan \\ Fuzhou University of International Studies and Trade \\ Fuzhou, China
}

\begin{abstract}
In recent years, the lack of social responsibility of many private enterprises has caused a series of problems and has a great impact on economic construction. Based on the social phenomenon, this paper argues that Chinese enterprises should enhance the awareness of public contribution and balance the relationship between employees and society. On the basis of summarizing domestic and foreign literature, this paper establishes a model to study the relationship between public contribution, employee satisfaction and corporate performance. The author designed a set of questionnaires and selected some employees of enterprises in the province. SPSS20.0 was used to analyze the results of the study, and verify the relationship between corporate public contribution, employee satisfaction and enterprise performance.
\end{abstract}

Keywords-public contribution; employee satisfaction; business performance

\section{INTRODUCTION}

\section{A. Current Research Status of Domestic and Foreign Research on Public Contribution}

Regarding the content of public contribution, domestic and foreign scholars have carried out extensive and in-depth discussions. Uodfrey (2005) mainly analyzes the reputation of the company from the theoretical level. He believes that corporate reputation is an intangible asset of the enterprise and can create greater economic benefits for the enterprise. Moreover, the better the reputation, the easier it is for companies to obtain superior resources from the market and achieve healthy development. There are also many foreign scholars who agree with this view. Brammer (2004) believes that corporate public contribution can be seen as an intrinsic factor in corporate reputation. Guo Yi (2019) believes that corporate public contribution in China is undergoing a transition from exogenous to endogenous, extensive to refined and compliance to strategic. Theoretical research is also topical, interdisciplinary, and cross-cultural. Amongst other development trends [1], Zhang Xuehui and Peng Jianyu (2019) believe that enterprises with higher R\&D investment usually reduce debt financing in order to avoid higher capital costs and financial risks [2]. These companies tend to favor internal financing and external equity financing. The negative correlation between $R \& D$ investment and capital structure is more pronounced in enterprises with high levels of corporate public contribution. Lu Xinguo (2019) believes that companies with managers who have experienced the "great famine" in the early years bear less corporate public contribution. Further analysis shows that the negative effects of managers' "great famine" experience on corporate public contribution exist only in private enterprises, but not in state-owned enterprises. Yang Jinlei (2019) believes that a good corporate public contribution performance can inhibit superfluous management behavior. Other extended researches also prove that corporate public contribution performance is a moral behavior and with the increase of instability of macroeconomic policy, the effect of inhibition of corporate public contribution performance on superfluous management will be reduced. Wang Zhanjie (2019) [3] believes that executive's compensation incentives play a negative role in regulating the relationship between corporate public contribution and internationalization strategy. Higher executive compensation incentives could lead to deeper influence of positive corporate social on internationalization strategy.

\section{B. Current Research Status of Chinese and Foreign Researches on Employee Satisfaction}

Employee satisfaction has always been the focus of organizational behavior research. Herzberg proposed the two-factor theory in 1966, which is the motivation-health factor theory. Then Locke considered employee satisfaction as reflect of emotion brought about by individuals completing certain tasks in his study in 1969, such as the recognition from leaders, the relationship among colleagues, the quality of managers, and various welfare benefits of enterprises. Yang Lulu (2019) believes that while taking into account their own development and improving employee performance, the company should establish a people-oriented and diversified personnel management policy thus enhance employees' work efficiency and work enthusiasm and maintain a stable internal development. Cheng Bao (2019) believes that organizational self-esteem plays an intermediary role in the relationship between over-qualified perception and employee professional satisfaction. Zhang Shuzhen (2019) believes that the satisfaction of employees in private enterprises in China is low and the brain drain is serious. The reason is that it is more and more difficult to 
meet the individualized needs of employees using the unified and equal enterprise welfare system, while a flexible welfare system that emphasizes flexible personality is missing in private enterprises in China. Han Wenjing (2019) believes that the degree of employee satisfaction is directly related to stability, enthusiasm and quality of their works, as well as the long-term prospect of the company. Especially for small and medium-sized private enterprises, the impact of employee satisfaction has far-reaching significance on the development of the enterprise and sometimes even plays a decisive role due to employees' own physical quantity, economic strength and the eager pursuit of their own development and other factors.

\section{Literature Review}

In summary, in terms of corporate public contribution, many scholars believe that corporate public contribution has a greater impact on corporate reputation and economic gains [4]. In terms of employee satisfaction, many scholars believe that employee satisfaction is affected by the overall personnel management policy of the company largely. And a lot of private enterprises in China have lower employee satisfaction and serious brain drain problems.

\section{RESEARCH HYPOTHESIS AND DATA MODEL}

In the above-mentioned literature, many domestic and foreign scholars believe that corporate public contribution has a greater impact on the economic interests of enterprises, and the degree of employee satisfaction with work is directly related to the stability, the enthusiasm and the quality of their work. Therefore, there is a close relationship between corporate public contribution, employee satisfaction and company performance. Based on the assumption, this paper constructs three dimensions, namely, corporate public contribution $\mathrm{X} 1$, employee satisfaction $\mathrm{X} 2$, and performance Y. In addition, three hypotheses are proposed: a positive correlation $\mathrm{H} 1$ between public contribution and performance, a positive correlation $\mathrm{H} 2$ between employee satisfaction and performance, and a positive correlation $\mathrm{H} 3$ between public contribution and employee satisfaction, as shown in the "Fig. $1 "$ :

\begin{tabular}{|c|c|c|c|c|}
\hline$\sqrt{v}$ & & & & $q$ \\
\hline $\begin{array}{l}\text { Corporate Public } \\
\text { Contribution } \mathrm{X} 1\end{array}$ & $\longleftarrow \mathrm{H} 1 \longrightarrow$ & Performance $\mathrm{Y}$ & $\longleftrightarrow \mathrm{H} 2 \longrightarrow$ & $\begin{array}{c}\text { Employee } \\
\text { Satisfaction X2 }\end{array}$ \\
\hline
\end{tabular}

Fig. 1. Relation between corporate public contribution, employee satisfaction and performance.

H1: positive correlation exists between public contribution and performance.

$\mathrm{H} 2$ : positive correlation exists between employee satisfaction and performance.

H3: positive correlation exists between public contribution and employee satisfaction.

\section{A. Description of Numbers and Indicators}

This paper collects materials by issuing questionnaires and distributing questionnaires while visiting. In order to ensure the quality of this questionnaire, this survey is conducted by means of stratified sampling, mainly for enterprises in Fujian Province. The survey individuals are mainly front-line employees and grassroots managers of enterprises. Answers to questionnaires are collected on the spot or by e-mail. A total of 150 questionnaires were distributed and 123 questionnaires were collected. The recovery rate was $82 \%$. 112 valid questionnaires were included after eliminating the invalid ones, and the valid rate was $91.1 \%$, which met the basic requirements of survey.

In this paper, 112 questionnaires were processed using SPSS 20.0 for data processing and statistical analysis. In terms of the industry classification, the food and beverage industry SMEs accounted for 35\%, the manufacturing SMEs accounted for $37 \%$, the wholesale and retail SMEs accounted for $21 \%$, and the others accounted for $7 \%$. In terms of the nature of the company, $20.4 \%$ of the employees are from partnerships, $28.4 \%$ are from sole proprietorships, and $51.2 \%$ are from limited liability companies. In terms of scale, enterprises with 200 employees or less account for $62 \%$, enterprises with employees between 200 and 500 account for $26 \%$, and enterprises with 500 or more account for $12 \%$. In terms of employees' job position, first-line employees accounted for $83.6 \%$ and line supervisors accounted for $16.4 \%$.

The standard of scoring for each data is as follows:

Corporate public contribution X1: Employees score their company's public contribution ranging from 0 points to 10 points.

Employee satisfaction X2: Employees score their job satisfaction ranging from 0 points to 10 points.

Performance $\mathrm{Y}$, the definition of job performance in the academic community is also different. Borman and Motowidlo once thought that job performance is evaluable. The research in this paper is based on that assumption. Employees score their own company's performance ranging from 0 points to 10 points.

\section{B. Correlation Analysis Between Public Contribution and Performance (HI)}

TABLE I. CORRELATION BETWEEN PUBLIC CONTRIBUTION AND PERFORMANCE

\begin{tabular}{|c|c|c|c|}
\hline & & $\begin{array}{c}\text { Public } \\
\text { Contribution X1 }\end{array}$ & $\begin{array}{c}\text { Performance } \\
\text { Y }\end{array}$ \\
\hline Public & $\begin{array}{l}\text { Pearson } \\
\text { correlation }\end{array}$ & 1 & $0.967 * *$ \\
\hline Contribution X1 & $\begin{array}{l}\text { Significant } \\
\text { (bilateral) }\end{array}$ & & 0.000 \\
\hline \multirow{2}{*}{ Performance Y } & $\begin{array}{l}\text { Pearson } \\
\text { correlation }\end{array}$ & $0.967 * *$ & 1 \\
\hline & $\begin{array}{l}\text { Significant } \\
\text { (bilateral) }\end{array}$ & 0.000 & \\
\hline
\end{tabular}

The result shows that the corporate public contribution is significantly related to company performance. The higher the corporate public contribution, the better the company's performance is. In recent years, many domestic private 
enterprises have frequently violated the law in business operations, causing widespread public concern. For example, the March, 15th party exposes companies manufacturing counterfeit and shoddy products, damaging the rights and interests of consumers, unfair competing between enterprises, delaying the payment of wages to migrant workers and infringing of intellectual property rights. The failure of these companies to fulfill their public contribution has also had a certain negative impact on corporate image, and some companies have even closed down. On the contrary, the correct implementation of public contribution can establish the image of the enterprise in the public, greatly enhance the competitiveness of the enterprise, help the long-term development of the enterprise, and increase the business performance of the enterprise.

According to the China Disabled Persons' Federation and Alibaba's big data, there are currently 174,100 disabled online stores in the Ali e-commerce platform, which have achieved sales of 29.84 billion Yuan in the past three years. According to data from the most recent year, from June 2018 to May 2019, the sales of disabled Taobao stores was \$11.6 billion. In addition to paying attention to the public welfare poverty alleviation of disabled people, on May 16 this year, Alibaba also announced the first "public welfare report" of the Alibaba economy. According to the "Public Welfare Report", in the last fiscal year, Alibaba employees used their spare time to do charity, accumulating 269,000 hours of public welfare, and the public welfare footprints were distributed in more than 20 countries and regions around the world. In addition, Alibaba is also the largest public welfare driving platform. In the Alibaba public welfare and Alipay public welfare platform, more than 9.1 billion public welfare donations were generated in the last fiscal year, and 440 million people were involved in public welfare. Of course, Alibaba's charity activities not only help disabled people, ant forests, charity babies, etc. These well-known public welfare activities have greatly enhanced its reputation and become an important part of Alibaba's sustainable development.

Founded in 1959, Carrefour is the pioneer of the hypermarket industry, the largest retailer in Europe and the second largest international retail chain in the world. Carrefour has been actively focusing on poverty alleviation and giving back to the society since its foundation. It is also an important part of Carrefour's practice of corporate public contribution. Through the orderly implementation of public welfare brand projects such as "direct investment poverty alleviation", "small loans", "infant and child nutrition package", "children's happy home" and "food bank", Carrefour has helped in 16 national poverty-stricken counties in 2018 and its efforts in poverty alleviation have been unanimously affirmed and appreciated. It was awarded the "Economic Excellence Award" by the European Union Chamber of Commerce in China, the "1818 CSR Competitiveness "Poverty Alleviation Model Award" and the 2018 CSR Pioneer Forum "Poverty Alleviation Model Award" And many other awards. Carrefour's fulfillment of public contribution has also greatly enhanced the company's reputation and promoted the development of the company.
On July 19, 2018, the Fortune Global 500 list was released, and Carrefour ranked 68th.

\section{Correlation Analysis Between Employee Satisfaction and Performance (H2)}

TABLE II. CORRELATION BETWEEN EMPLOYEE SATISFACTION AND PERFORMANCE

\begin{tabular}{|l|l|l|l|}
\hline \multicolumn{2}{|c|}{} & \multicolumn{1}{|c|}{$\begin{array}{c}\text { Employee } \\
\text { Satisfaction X2 }\end{array}$} & $\begin{array}{c}\text { Performance } \\
\text { Y }\end{array}$ \\
\hline Employee & Pearson correlation & 1 & $0.976^{* *}$ \\
\cline { 2 - 4 } Satisfaction X2 & Significance(bilateral) & & .000 \\
\hline Performance Y & Pearson correlation & $0.976^{* *}$ & 1 \\
\cline { 2 - 4 } & Significance(bilateral) & 0.000 & \\
\hline
\end{tabular}

The result shows that employee satisfaction is significantly correlated with corporate performance. High employee satisfaction can bring good performance to enterprises. Companies should improve employee satisfaction, and then improve company performance. Taking Haidilao as an example, Haidilao was originally a small chafing dish shop in Sichuan. Most of the front-line employees were post-80s or post-90s. They were mainly young people growing up in the countryside, had lower than average family conditions and not well educated. The enterprise has taken certain measures to establish schools to help its employees' children to go to school, improving employee satisfaction and loyalty. The fact proves that Haidilao has also developed from an unknown small chafing dish shop in Sichuan to a major chafing dish brand today. The management staff and employees of Haidilao live together in the same staff dormitory. All rooms are equipped with air conditioning, TV and computer. Special personnel management, cleaning, staff's overalls, quilts are also uniformly cleaned. When an employee is ill, the dormitory administrator will accompany him to see a doctor and take care of his diet. At the same time, all employees in Haidilao have additional bonuses besides basic salary as an encouragement to employees' good work performance. There are also a lot of creativity methods in Haidilao on the issue of respecting and treating employees well. For example, the company sends bonuses of prominent employees directly to their parents. Therefore, high employee satisfaction will have a positive impact on the production and operation of enterprises, and it is significantly related to corporate performance.

\section{Correlation Analysis Between Public Contribution and Employee Satisfaction (H3)}

TABLE III. CORRELATION BETWEEN PUBLIC CONTRIBUTION AND EMPLOYEE SATISFACTION

\begin{tabular}{|c|c|c|c|}
\hline & \begin{tabular}{|c|} 
Public \\
Contribution X1 \\
\end{tabular} & \begin{tabular}{|c|} 
Employee \\
Satisfaction X2
\end{tabular} \\
\hline \multirow{2}{*}{\begin{tabular}{|l} 
Public \\
Contribution \\
X1
\end{tabular}} & Pearson correlation & 1 & $0.991 * *$ \\
\hline & $\begin{array}{l}\text { Significance } \\
\text { (bilateral) }\end{array}$ & & .000 \\
\hline \multirow{2}{*}{$\begin{array}{l}\text { Employee } \\
\text { Satisfaction X }\end{array}$} & Pearson correlation & $0.991 * *$ & 1 \\
\hline & $2 \begin{array}{l}\text { Significance } \\
\text { (bilateral) }\end{array}$ & 0.000 & \\
\hline
\end{tabular}


After verifying the relationship between $\mathrm{X} 1$ and $\mathrm{X} 2$ and $\mathrm{Y}$, this paper also verifies that public contribution and employee satisfaction are positively correlated. In other words, practice has proved that employee satisfaction is closely related to corporate public contribution. The better the performance of public contribution, the higher the employee satisfaction is. It shows that in order to improve employee satisfaction, enterprises must improve their moral perception and take public contribution seriously. While gaining profits and assuming legal responsibilities to shareholders, enterprises should also assume responsibilities to employees, consumers, communities and the environment. For example, whether enterprises can pay attention to save resources, adjust their structure and raise awareness of environmental protection while developing? Whether enterprises as social citizens can pay taxes according to law, accept legal supervision? The answer to these questions will greatly affect the pride and honor of employees and improve employee satisfaction.

By the end of 2018, Meituan had served 400 million users, covering more than 200 fields including catering, takeaway, hotel travel, leisure and entertainment, and shared bicycles. Its business covers a total number of 2,800 cities in many countries. According to the report data, one out of every two Chinese netizens has consumed at least once using the apps of Meituan in 2018. In the meanwhile, about 7.51 million medical staff called Meituan to send their patients to the hospital in 2018. Meituan also helped more than 14 million white-collar workers who worked busy until $8 \mathrm{pm}$ and had no time for cooking. According to research data from a research group of Chinese Renmin University, the Meituan has created 19.6 million employment opportunity including 2.7 million jobs and over 16 million business opportunities for merchants, take-away rider and other related industry. The fulfillment of the social responsibility of the Meituan has greatly improved the job satisfaction of its employees and promoted the long-term development of the company.

\section{E. Test Results}

TABLE IV. HyPOTHESIS TEST RESUlTS

\begin{tabular}{|l|l|c|}
\hline \multicolumn{1}{|c|}{ Hypothetical proposition } & \\
\hline $\boldsymbol{H 1}$ & $\begin{array}{l}\text { Positive correlation exists between public } \\
\text { contribution and performance }\end{array}$ & True \\
\hline $\boldsymbol{H 2}$ & $\begin{array}{l}\text { Positive correlation exists between employee } \\
\text { satisfaction and performance }\end{array}$ & True \\
\hline $\boldsymbol{H 3}$ & $\begin{array}{l}\text { Positive correlation exists between public } \\
\text { contribution and employee satisfaction }\end{array}$ & True \\
\hline
\end{tabular}

The result shows that the relationship between corporate public contribution, employee satisfaction and performance is consistent with the research hypothesis. The three factors are dialectically united and closely related. Therefore it is very important for enterprises to correctly handle the relationship between the three factors.

\section{CONCLUSION}

Private enterprises are listed as the research object in this paper. At present, many studies have been formed to explore public contribution of large enterprises and state-owned enterprises, while few studies have been devoted to private enterprises. Private entrepreneurs often only seek their own profits and care nothing about employees or their surrounding environment. And the lack of public contribution often results in a series of problems that are hard to ignore [5]. Practice has proved that the lack of public contribution in many private enterprises do affect employees job satisfaction, and reduce the overall performance of the enterprise [6]. Especially in today's society, many enterprises have been pushed to the forefront because of environmental pollution problems, and have been named for rectification. Enterprises that do not pay attention to these problems will inevitably cause employees' dissatisfaction [7]. Therefore, private enterprises should improve their sense of public contribution, deal with the relationship between themselves, employees and society, and take the issue of fulfilling public contribution seriously for the long-term development of enterprises.

Employee satisfaction is a kind of psychological perception activity and a subjective judgment of value [8]. In fact, it is composed of many factors of the enterprise, such as whether the enterprise operates in accordance with the law, whether it is honest, whether it abides by professional ethics, whether it can protect the legitimate rights and interests of employees and whether the working environment is comfortable and so on. If the employee's feeling greatly exceeds his/her expectations, the employee's job satisfaction will be relatively high, and vice versa. Therefore, private enterprises should meet the internal and external needs of employees in various ways and provide some additional treatment and care for employees, such as birthday celebration, promotion of corporate culture, establishment of maternal and infant rooms and improvement of dining standards in canteens in order to create a comfortable working environment, improve employee satisfaction and mobilize the enthusiasm of employees [9]. High employee satisfaction can also bring good performance for enterprises [10]. It is worth mentioning that in addition to improving employee satisfaction with further treatment, enterprises should also take social relations into consideration. Some enterprises cheat consumers by producing fake goods, failing to meet the quality standards, employing child workers and destroying the surrounding environment. Those actions would greatly reduce employee satisfaction and lead to the instability of the staff and affect the performance of the enterprise.

Private enterprises should have a long-term strategic vision, handle the relationship between the company, its employees and the society, and should not sacrifice longterm interests at the expense of short-term interests. Many private entrepreneurs refuse to use long-term incentive mechanism in employment, such as stock option, employee stock ownership, length of service salary and so on. Longterm incentive mechanism is seldom used in private enterprises, which to a certain extent lowers the enthusiasm, 
initiative and creativity of senior managers, and affects employee satisfaction. Some problems are also due to lack the sense of public contribution, such as the mine disaster in Shanxi Province, the frequent employment of child labor, environmental pollution caused by factory operation and so on[11]. Fact has proved that private enterprises with these problems would not develop greatly in the long run. Enterprises cannot develop without the society and it is the responsibility of enterprises to pay back to society. For instance, Jingdong uses technology such as drones, smart supply chains, big data, VR technology as well as block chain technology to promote the integration between technology and public welfare, and focus on poverty alleviation, education, disaster relief, environmental protection and social innovation. Using the vitality of the "Internet + Public Welfare" model, children's books that have been sorted and sent to more than 200 elementary schools in the rural areas of China as Children's Day gifts. The books have been sent to as far as Xinjiang Kashgar Primary School. In addition, some enterprises create more jobs and employ those who are laid-off and unemployed. This is also a manifestation of fulfilling public contribution. Higher performance of corporate public contribution can also enhance the reputation of enterprises, therefore improve employee satisfaction, and gain social and economic benefits. All of which could lead to a stable and sustainable development of enterprises. On the contrary, if the enterprise cannot coordinate well from the interests of all aspects, the narrow-mindedness will ultimately deteriorate the long-term development of the enterprise. That is to say, private enterprises should have a long-term strategic vision, handle their relationship with employees and society and not sacrifice long-term interests for short-term interests.

\section{REFERENCES}

[1] Guo Yi. A bibliometric analysis of corporate public contribution research in China from 1998 to 2018 [J]. Journal of Beijing Jiaotong University (Social Science Edition), 2019 (02), 78-88.

[2] Zhang Xuehui. The impact of corporate public contribution level and R\&D investment on Capital Structure - Based on empirical analysis of SME listed companies in China [J]. Friends of Accounting, 2019 (07), 96-100.

[3] Wang Zhanjie. Corporate Public Contribution, Innovation Ability and Internationalization Strategy: Regulating Role of Executive Compensation Incentive [J]. Management Review. 2019 (03), 193202

[4] Li Wenxi, Liu Yi. Technological Innovation, Corporate Public Contribution and Corporate Competitiveness: An Empirical Analysis Based on the Data of Listed Companies [J]. Science and Technology Management. 2017 (01).

[5] Zhong Zhendong, Wang Yunlong. Empirical Study on Corporate Public Contribution and Technological Innovation Investment Based on Stakeholder Perspective [J]. Science, Technology and Economy. 2018 (03).

[6] Bram Steijn, Joris van der Voet. Relational job characteristics and job satisfaction of public sector employees: When prosocial motivation and red tape collide [J]. Public Administration, 2019(3).

[7] Gayani Hewagama, Peter Boxall, Gordon Cheung, Ann Hutchison. Service recovery through empowerment? HRM, employee performance and job satisfaction in hotels [J]. International Journal of Hospitality Management, 2019 (3).
[8] Ai-Jane Huang, Wan-Lin Hsieh, Chung-Yu Pan, Hsiu-Ho Wang, O.U. Shiang-Ferng. Employee training does matter: A systematic evaluation of the application of HFMEA in instrument sterilization procedures[J]. Journal of Microbiology, Immunology and Infection. 2015(2).

[9] Wan-Lin Hsieh, Yii-Ching Lee, Chih-Hsuan Huang, Hsin-Hung Wu, Shao-Jen Weng. Revisit employee satisfaction scale: a case study of the regional teaching hospital[J]. Total Quality Management \& Business Excellence. 2019(5-6).

[10] Alexander Newman, Qing Miao, Peter S. Hofman, Cherrie Jiuhua Zhu. The impact of socially responsible human resource management on employees' organizational citizenship behavior: the mediating role of organizational identification[J]. The International Journal of Human Resource Managerment. 2016(4).

[11] M. Rosario González-Rodríguez, M. Carmen Díaz-Fernández, Biagio Simonetti. The social, economic and environmental dimensions of corporate social responsibility: The role played by consumers and potential entrepreneurs [J]. International Business Review. 2015(5). 